\title{
Right and Left Ventricular Takotsubo: Same Two- Headed Monster or Different Beasts?
}

\author{
Hajir Zohourian ${ }^{1}$ \\ 1. Heart Center of Excellence, Broward Health Medical Center, Fort Lauderdale, USA
}

Corresponding author: Hajir Zohourian, nsuhajir@gmail.com

\begin{abstract}
Right ventricular involvement in takotsubo cardiomyopathy is poorly understood and may be more common than previously reported. The significant hemodynamic ramification of this condition is elicited in this case report in which an 81-year-old female suffered a deadly biventricular takotsubo cardiomyopathy with subsequent resolution of left ventricular function but the persistence of right ventricular dysfunction. In this case, we highlight the importance of shifting focus to different recovery patterns within the two ventricles. Through a review of published cases, we have found an absence of attention to the right ventricle, an inconsistency in the appropriate diagnostic criteria of right ventricular takotsubo, and a lack of reporting on its recovery timing. This knowledge gap requires future studies.
\end{abstract}

Review began $11 / 26 / 2020$ Review ended 12/21/2020 Published 12/22/2020

\section{(c) Copyright 2020}

Zohourian. This is an open access article distributed under the terms of the Creative Commons Attribution License CC-BY 4.0., which permits unrestricted use, distribution, and reproduction in any medium, provided the original author and source are credited.
Categories: Anesthesiology, Cardiology, Internal Medicine

Keywords: takotsubo syndrome, right ventricular dysfunction, biventricular dysfunction, stress cardiomyopathy, wall motion abnormality, ventriculography

\section{Introduction}

Although there are few cases of isolated right ventricular takotsubo and biventricular involvement reported in publications as case reports, almost all demonstrate similar limitations in the follow-up imaging techniques to evaluate for accurate timing of recovery of the right ventricle alone or in correlation with the left ventricle. In most studies, the monitoring with a serial echocardiogram and cardiovascular magnetic resonance imaging (CMR) to confirm for recovery of ventricular function often occurred weeks after the initial diagnosis, leaving the question of exact time of recovery unanswered. The International Expert Consensus Document published in 2018 on takotsubo cardiomyopathy (TTC) expresses the concern for the presence of concomitant right ventricular involvement and how little information is known on the subject of right ventricular takotsubo [1]. This lack of information is in part due to the current design of studies, either omitting or not performing adequate imaging at shorter time intervals to investigate for right ventricular dysfunction and its recovery in correlation to the left ventricle. Thus, the timing of recovery of left versus right ventricle has not been truly investigated.

Whether the pathology of right ventricular involvement is an extension of the left ventricle or has its own unique pattern is not clear. The true diagnostic criteria for right ventricular takotsubo are not yet defined. Such criteria are essential to distinguish a true right ventricular takotsubo from either a preexisting right ventricular wall motion abnormality (WMA) in a normal subject or due to the effect of tethering from apical involvement of left ventricular takotsubo.

This article presents a case that shows that the timing of recovery for the left and right ventricle may be different. In addition, with the review of published cases, we identify the gap in knowledge and limitations in previous investigations.

\section{Case Presentation}

An 81-year-old female with recurrent symptomatic paroxysmal atrial fibrillation who had failed prior atrial fibrillation ablations and antiarrhythmics for rhythm management was admitted for elective atrioventricular nodal ablation. Her presenting blood pressure was $140 / 80 \mathrm{mmHg}$, and laboratory data was stable at her baseline with hemoglobin $9 \mathrm{~g} / \mathrm{dL}$ and creatinine $1.4 \mathrm{mg} / \mathrm{dL}$. Her electrocardiogram was noted in atrial fibrillation with a rapid ventricular rate of 110 beats per minute (bpm). The atrioventricular nodal ablation and insertion of a dual-chamber permanent pacemaker were successful. Two hours after the procedure, she experienced a sudden shortness of breath and hypotension. Her new blood pressure was $88 / 42 \mathrm{mmHg}$, and her heart rate was $80 \mathrm{bpm}$ (the heart rate was set by the pacemaker). On physical exam, jugular venous distention was noted at $9 \mathrm{~cm} \mathrm{H2O}$, and holosystolic murmur of grade $3 / 6$ was heard at the apex.

The differential diagnosis for this sudden respiratory insufficiency and hypotension after an atrioventricular nodal ablation is extensive but includes pericardial tamponade, pulmonary embolism, stunned myocardium, retroperitoneal bleeding, and ischemia from a plaque rupture. 


\section{Cureus}

Electrocardiogram was performed and showed new T wave inversions in inferior leads (II, III, aVF) but no ST-segment changes, which were difficult to assess due to underlying paced rhythm. Arterial blood gas showed adequate oxygenation with the partial pressure of oxygen (PaO2) of $123 \mathrm{mmHg}$ on a fraction of inspired oxygen (FiO2) of 30\%, placing pulmonary embolism on a lower differential diagnosis. Transthoracic echocardiogram (TTE) with contrast was performed and showed biventricular TTC (Figure 1, Video 1). The patient's previous TTE three months ago showed normal left and right ventricular systolic function. Repeat laboratory workup revealed troponin-I of $1.45 \mathrm{ng} / \mathrm{ml}$ and brain natriuretic peptide of $1329 \mathrm{pg} / \mathrm{ml}$.

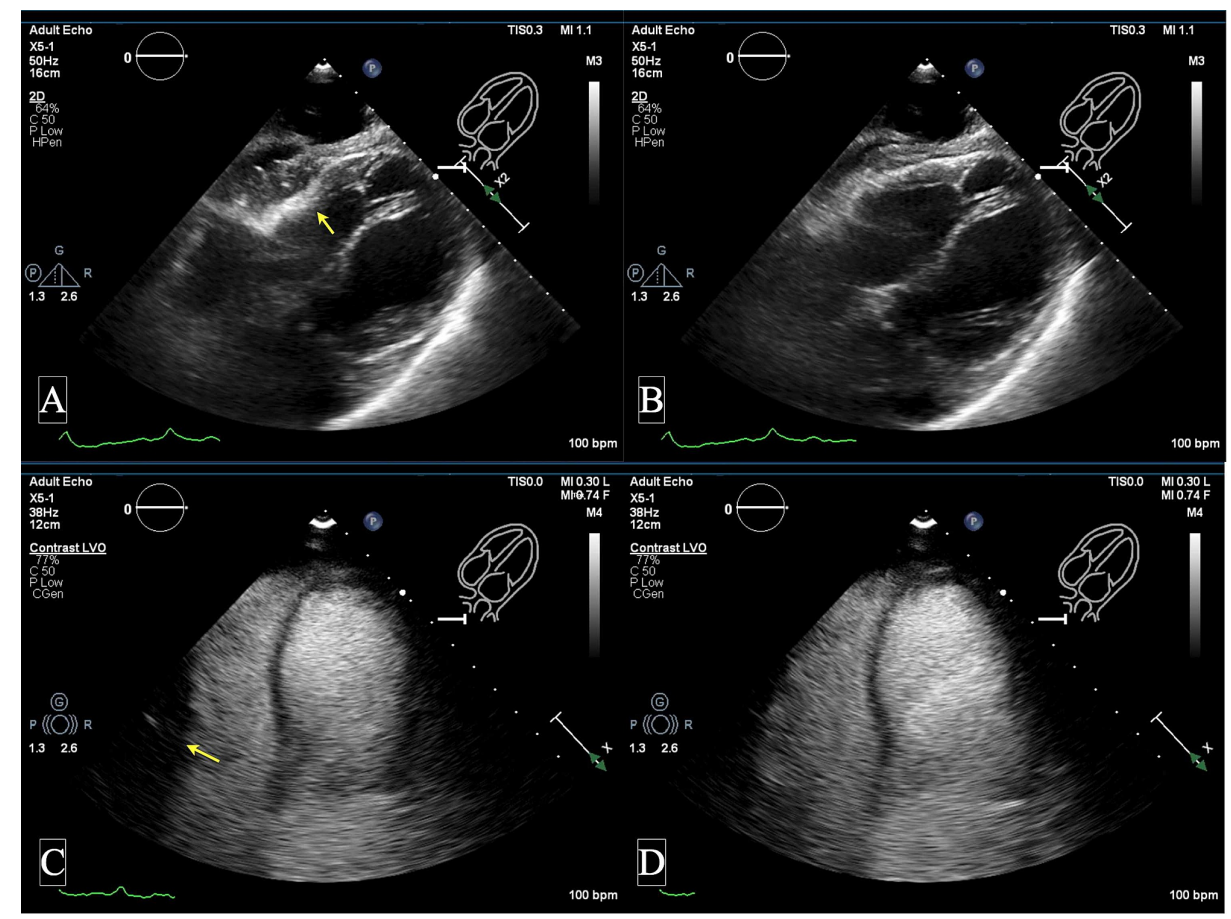

FIGURE 1: TTC: subcostal view without contrast and apical view with contrast

Images are showing subcostal view without contrast (A-B); apical four-chamber view with contrast (C-D) showing biventricular takotsubo with apical akinesias and hyperdynamic basal segment (marked by the yellow arrow).

TTC - takotsubo cardiomyopathy

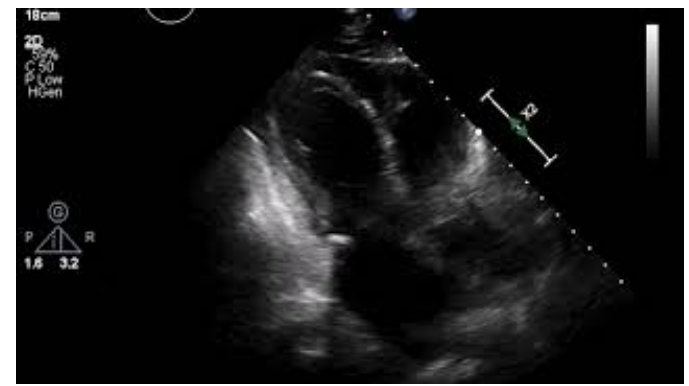

VIDEO 1: TTC: apical four-chamber view with contrast

Video is showing biventricular takotsubo with apical akinesia in both LV and RV.

TTC - takotsubo cardiomyopathy; LV - left ventricle; RV - right ventricle

View video here: https://youtu.be/zS25fb1ITo4

In the setting of right ventricular failure and preload dependence, 1-liter intravenous normal saline fluid recitation improved her blood pressure temporarily. Hours later, she deteriorated with a decline in mentation, poor perfusion, and blood pressure of $63 / 51 \mathrm{mmHg}$ requiring initiation of dobutamine 10 $\mathrm{mcg} / \mathrm{kg} / \mathrm{min}$ and norepinephrine $0.2 \mathrm{mcg} / \mathrm{kg} / \mathrm{min}$. Multiple attempts to wean-off norepinephrine and 


\section{Cureus}

switching dobutamine to milrinone were unsuccessful. Manual change in pacemaker setting to increase heart rate to $100 \mathrm{bpm}$ did not make any significant difference in her hemodynamics. At this point, left heart catheterization was performed, confirming mild non-obstructive coronary artery disease. An intra-aortic balloon pump with 1:1 augmentation was utilized. Series of echocardiograms were performed daily. Left ventricle WMA completely resolved on day 3, while the right ventricle apical akinesia and basal hyperkinesis persisted with some improvement (Figure 2, Video 2). Repeat hemodynamic assessment in the cardiac catheterization laboratory showed left ventricle end-diastolic pressure of $14 \mathrm{mmHg}$, pulmonary artery pressure 38/22 $\mathrm{mmHg}$, right ventricle (RV) pressure of $37 / 11 \mathrm{mmHg}$, and mean right atrial pressure of 20 $\mathrm{mmHg}$. Unfortunately, with concomitant sepsis and progression of multiorgan failure, the patient expired on day 5 .

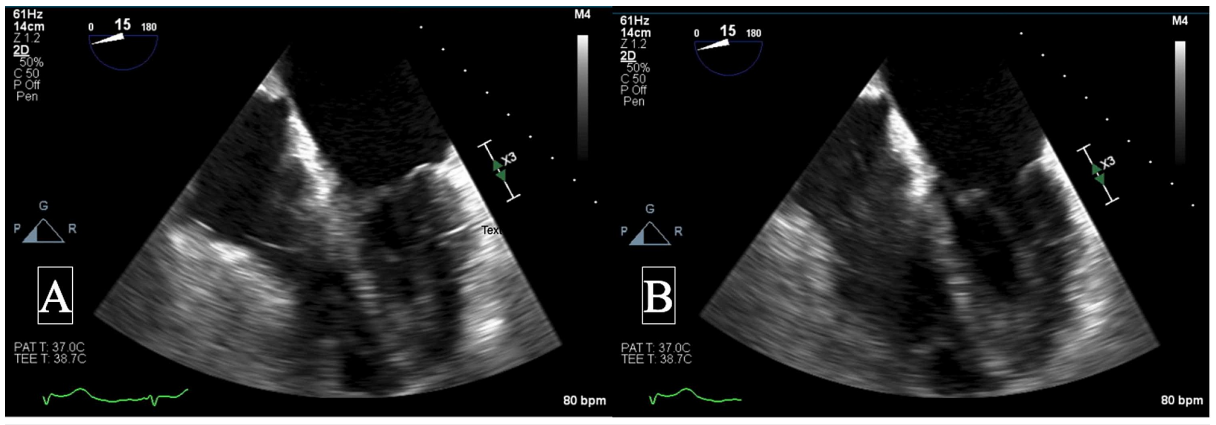

\section{FIGURE 2: TEE: mid-esophageal four-chamber view}

Images are showing left ventricle (LV) systolic function recovery but persistent right ventricle (RV) apical akinesia in systolic phase (A) and diastolic phase (B).

TEE - transthoracic echocardiogram

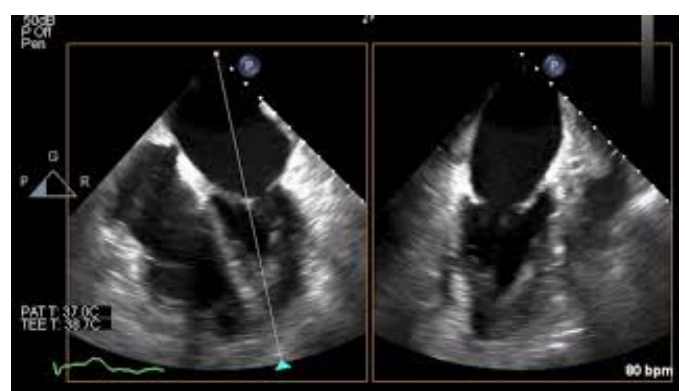

VIDEO 2: TEE: mid-esophageal four-chamber view and two imaging planes of LV

Left ventricle (LV) systolic function has recovered, while the right ventricle (RV) apical akinesia persists.

View video here: https://youtu.be/8PNedGBhBqU

\section{Discussion}

This case highlights the observation of differing recovery times amongst the left ventricle and right ventricle in TTC. This observation was possible due to serial daily echocardiograms. While biventricular TTC has been reported in the literature, the recovery pattern has not been clearly elicited. Whether the same mechanisms proposed to explain left ventricular function in TTC apply to the right ventricle is unknown.

We performed an extensive electronic search in current literature and cross-referenced all published studies. After excluding studies that lacked adequate follow-up imaging modalities, we identified 14 reports that pertained to either biventricular or isolated right ventricular TTC. This review encompasses 21 total individual cases and observed "isolated" right ventricular TTC as a significant minority (Table 1). 


\begin{tabular}{|c|c|c|c|c|c|c|c|c|c|c|c|c|}
\hline Report & $\begin{array}{l}\text { No. } \\
\text { Pts. }\end{array}$ & Age & Sex & RV/LV & $\begin{array}{l}\text { Initial } \\
\text { LVEF }\end{array}$ & $\begin{array}{l}\text { Time to } \\
\text { improve }\end{array}$ & $\begin{array}{l}\text { Time to } \\
\text { normal }\end{array}$ & ECG & CE & $\begin{array}{l}\text { RV } \\
\text { type }\end{array}$ & $\begin{array}{l}\text { LV } \\
\text { type }\end{array}$ & Modality \\
\hline $\begin{array}{l}\text { Elesber AA et al. } \\
\text { [3] }\end{array}$ & 8 & $\begin{array}{l}70 \pm \\
13\end{array}$ & - & Both & $29 \% \pm 9$ & - & $86 \pm 115 d$ & - & - & Apical & - & TTE \\
\hline Haghi D et al. [4] § & 9 & $70 \pm 8$ & $8 \mathrm{~F} / 1 \mathrm{M}$ & Both & $\begin{array}{l}40 \% \pm \\
0.06\end{array}$ & $6-905 \mathrm{~d}$ & - & $\begin{array}{l}\mathrm{T} \downarrow(5) ; \\
\mathrm{ST} \uparrow \downarrow(4)\end{array}$ & Positive & - & - & CMR \\
\hline $\begin{array}{l}\text { Nishikawa S et al. } \\
\text { [6]? }\end{array}$ & 1 & 84 & $\mathrm{~F}$ & Both & $33 \%$ & $14 \mathrm{~d}$ & $30 \mathrm{~d}$ & ST $\uparrow$ & Positive & Apical & Apical & $\begin{array}{l}\text { TTE, SPECT, } \\
\text { LVG/RVG }\end{array}$ \\
\hline Nyui $\mathbf{N}$, et al. $[9]^{*}$ & 1 & 82 & $\mathrm{~F}$ & Both & - & $8 \mathrm{~d}$ & $35 \mathrm{~d}$ & ST $\uparrow$ & - & Apical & Apical & TTE, LVG/RVG \\
\hline $\begin{array}{l}\text { Kagiyama N et al. } \\
\text { [10] }\end{array}$ & 1 & 89 & $F$ & RV & normal & $14 \mathrm{~d}$ & $14 \mathrm{~d}$ & - & Positive & Basal & Normal & CMR, TTE \\
\hline $\begin{array}{l}\text { Donohue D et al. } \\
{[11]^{\star}}\end{array}$ & 1 & 67 & $\mathrm{~F}$ & Both & - & $7 \mathrm{~d}$ & $7 \mathrm{~d}$ & $T \downarrow$ & Positive & Apical & Apical & TTE \\
\hline $\begin{array}{l}\text { Akashi YJ et al. } \\
{[12]^{\star} \dagger}\end{array}$ & 1 & 67 & $F$ & Both & $51 \%$ & $14 \mathrm{~d}$ & $14 \mathrm{~d}$ & ST $\uparrow$ & Positive & Apical & Apical & TTE, LVG/RVG \\
\hline Novak G et al. [13] & 1 & 65 & $\mathrm{~F}$ & Both & $18 \%$ & $4 \mathrm{~d}$ & $12 \mathrm{~d}$ & $T \downarrow$ & Positive & Apical & Apical & TTE \\
\hline Bär H et al. [14] & 1 & 80 & $\mathrm{~F}$ & Both & reduced & $7 \mathrm{~d}$ & $7 d$ & $T \downarrow$ & Positive & Apical & Apical & TTE \\
\hline $\begin{array}{l}\text { Korlakunta } \mathrm{H} \text { et al. } \\
\text { [15] }\end{array}$ & 1 & 89 & $\mathrm{~F}$ & Both & reduced & $4 \mathrm{wk}$ & $4 \mathrm{wk}$ & None & Positive & Apical & Apical & CMR \\
\hline $\begin{array}{l}\text { Akashi YJ et al. } \\
\text { [16] }\end{array}$ & 1 & 79 & $\mathrm{~F}$ & Both & - & $3 \mathrm{mo}$ & $3 \mathrm{mo}$ & ST $\uparrow$ & - & Apical & Basal & TTE, CMR \\
\hline Novak G et al. [17] & 1 & 78 & $\mathrm{~F}$ & Both & $44 \%$ & $14 \mathrm{~d}$ & $14 \mathrm{~d}$ & ST $\uparrow$ & Positive & Apical & Apical & TTE, LVG/RVG \\
\hline Citro R et al. [18] & 1 & 81 & $\mathrm{~F}$ & RV & - & $18 d$ & $18 \mathrm{~d}$ & $T \downarrow$ & Positive & - & Apical & TTE \\
\hline Daoko J et al. [19] & 1 & 62 & $\mathrm{~F}$ & Both & $10 \%$ & $9 \mathrm{~d}$ & $5 \mathrm{wk}$ & $T \downarrow$ & Positive & Apical & Apical & TTE \\
\hline $\begin{array}{l}\text { Mrdovic let al. } \\
\text { [20] }\end{array}$ & 1 & 49 & $\mathrm{~F}$ & RV & - & $4 \mathrm{~d}$ & $4 \mathrm{~d}$ & $T \downarrow$ & Negative & Apical & - & TTE \\
\hline
\end{tabular}

\section{TABLE 1: Review of published cases}

CE - cardiac enzyme; CMR - cardiac magnetic resonance; d - days; ECG - electrocardiogram; F - Female; LV - left ventricle; LVEF - left ventricular ejection fraction; LVG - left ventriculography; M - Male; mo - months; wk - weeks; Pts - patients; RV - right ventricle; RVG - right ventriculography; SPECT - single-photon emission computed tomography; ST $\uparrow$ - ST segment elevation; ST $\uparrow \downarrow$ - ST segment elevation and depression; T $\downarrow$ - T wave inversions; TTE - transthoracic echocardiogram; Apical - apical wall akinesia/hypokinesis; Basal - basal wall akinesia/hypokinesis; WMA - wall motion abnormality

* LV function improved. No mention of RV improvement.

† Cardiac biopsy showed evidence for chronic myocarditis.

$\S$ Follow up in eight out of nine pts. RV WMA resolved in five pts and improved in three out of eight pts.

? LV function improved from $33 \%$ to $48 \%$ after 30 days. RV dysfunction persisted.

While there are several variants of TTC, isolated left ventricular involvement has been the main focus in current literature. Unfortunately, the presence of concomitant right ventricular dysfunction was not accounted for in large systemic reviews on TTC [2]. Although right ventricular involvement has been reported sparsely, common clinical practice has yet to adjust for a more routine evaluation of right ventricular function. The prevalence of right ventricular involvement may be much higher than the previously presumed at $27 \%[3,4]$.

The few publications that report right ventricular involvement in TTC, have significant limitations in the modality of imaging and poorly structured follow up. Limitation of imaging modality was evident in a study performed by Elesber et al. [3]. Out of 25 patients, eight patients were identified to have TCC with right ventricular involvement using visual assessment with an echocardiogram. However, out of an additional set 
of five patients that were assessed using CMR, four patients (80\%) were noted to have right ventricular involvement. It raises the question: would the right ventricular dysfunction that was diagnosed with CMR have been diagnosed with the echocardiogram modality? Additionally, using TTC modalities such as tricuspid annular systolic excursion (TAPSE) and right ventricular fractional area change (RVFAC) have shown significant limitations due to compensating hyperdynamic wall motion in TTC and innate inaccuracy in the assessment of global right ventricular function in a single plane respectively [5].

Likewise, this limitation on follow-up was evident across several cases through our search of current literature. For example, three reports did not mention whether the right ventricular function improved at all. One report had eight out of nine patients with actual follow-up imaging. One isolated report showed that while left ventricular function improved from $33 \%$ to $48 \%$, the right ventricular dysfunction persisted at 30 days [6]. Based on this finding, they postulated that biventricular TTC may take longer for recovery. In a report by Haghi et al., three out of eight patients with right ventricular involvement had partial improvement in function within six to 10 days, perhaps with repeat imaging done too early [4]. Similar to the above cases, our case also points toward a trend that the left and right ventricular recovery times may differ. However, there are no other cases that had follow-up imaging setup in a way to account for this discordance in recovery.

It is crucial to note that right ventricle WMA may also coincidently exist in subjects with left ventricular TTC that may not be related to either the right or left ventricular TTC. Sievers et al. demonstrated that up to $41.4 \%$ of healthy subjects had a right ventricular WMA in a modified horizontal longitudinal plane performed with CMR [7]. Therefore, it is imperative for future studies to consider the sensitivity of CMR in the assessment of wall motion. Some of these wall motion abnormalities are pre-existing conditions that are incidentally discovered at the time of investigating for TTC. Therefore, it is necessary to have adequate follow-up imaging to ensure that the right ventricular function recovers in order to exclude unrelated diagnoses and confirm the true diagnosis of right ventricular TTC.

Two variations of right ventricular WMA have been reported with several imaging modalities in patients with TTC. The akinetic or hypokinetic wall motion has been observed in either the apical or basal segments of the right ventricle. The basal variant is relatively rare (Table 1). The more common apical variant has a distinct right ventricular WMA that is described as hyperkinesis of the base and midsegment of the right ventricle free wall and hypokinesis of the apical wall. This feature was termed a "reverse McConnell's sign" in a short manuscript by Liu et al. [8]. It is postulated that the hyperkinetic segment of the right ventricle free wall may simply be a physiological response to increase preload to a poor left ventricle systolic function in maintaining the cardiac output. Additionally, the hypokinesis at the apex may be due to a tethering effect from a neighboring akinetic left ventricle apex [8]. Thus, there may be a possibility that some types of right ventricle WMA may not be due to right ventricle failure but rather appear secondary to isolated left ventricle dysfunction. This observation suggests that additional studies are required to determine true diagnostic criteria for the right ventricle involvement in TTC that goes beyond visualization of WMA.

\section{Conclusions}

The most crucial factor in diagnosing takotsubo cardiomyopathy with right ventricular involvement has a lower threshold in identifying wall motion abnormality within the right ventricle using any available imaging modality at the time of presentation. For example, the addition of a right heart ventriculogram to the usual left ventriculography should be considered and reported in future manuscripts. Study design should consider repeat imaging modalities at shorter interval periods in order to provide added information with respect to the timeline of recovery and comparison between the two ventricles. Through this case series and review of existing literature, we illustrate the gaps in knowledge and the importance of having a diagnostic criterion for right ventricular wall motion abnormality consistent with a true takotsubo cardiomyopathy. We suggest there should be an awareness of the possibility of preexisting right ventricular wall motion abnormality that is not related to takotsubo cardiomyopathy. The incidence of right ventricular involvement in takotsubo cardiomyopathy is not scarce, and its diagnosis holds important clinical implications. We recommend future studies to shift focus onto differences in left and right ventricular recovery patterns so that it can be better identified and understood.

\section{Additional Information \\ Disclosures}

Human subjects: Consent was obtained by all participants in this study. Conflicts of interest: In compliance with the ICMJE uniform disclosure form, all authors declare the following: Payment/services info: All authors have declared that no financial support was received from any organization for the submitted work. Financial relationships: All authors have declared that they have no financial relationships at present or within the previous three years with any organizations that might have an interest in the submitted work. Other relationships: All authors have declared that there are no other relationships or activities that could appear to have influenced the submitted work.

\section{References}


1. Ghadri J-R, Wittstein IS, Prasad A, et al.: International expert consensus document on Takotsubo syndrome (part I): clinical characteristics, diagnostic criteria, and pathophysiology. Eur Heart J. 2018, 39:2032-2046. 10.1093/eurheartj/ehy076

2. Gianni M, Dentali F, Grandi AM, Sumner G, Hiralal R, Lonn E: Apical ballooning syndrome or Takotsubo cardiomyopathy: a systematic review. Eur Heart J. 2006, 27:1523-1529. 10.1093/eurheartj/ehl032

3. Elesber AA, Prasad A, Bybee KA, et al.: Transient cardiac apical ballooning syndrome: prevalence and clinical implications of right ventricular involvement. J Am Coll Cardiol. 2006, 47:1082-1083. 10.1016/j.jacc.2005.12.004

4. Haghi D, Athanasiadis A, Papavassiliu T, et al.: Right ventricular involvement in Takotsubo cardiomyopathy . Eur Heart J. 2006, 27:2433-2439. 10.1093/eurheartj/ehl274

5. Heggemann F, Hamm K, Brade J, et al.: Right ventricular function quantification in Takotsubo cardiomyopathy using two-dimensional strain echocardiography. Plos One. 2014, 9:e103717. 10.1371/journal.pone.0103717

6. Nishikawa S, Ito K, Adachi Y, Katoh S, Azuma A, Matsubara H: Ampulla ('Takotsubo') cardiomyopathy of both ventricles. Circ J. 2004, 68:1076-1080. 10.1253/circj.68.1076

7. Sievers B, Addo M, Franken U, Trappe H: Right ventricular wall motion abnormalities found in healthy subjects by cardiovascular magnetic resonance imaging and characterized with a new segmental model. J Cardiovasc Magn Reson. 2004, 6:601-608.

8. Liu K, Carhart R: “Reverse McConnell's sign?”: a unique right ventricular feature of Takotsubo cardiomyopathy. Am J Card. 2013, 111:1232-1235. 10.1016/j.amjcard.2012.12.007

9. Nyui N, Yamanaka O, Nakayama R, Sawano M, Kawai S: 'Tako-Tsubo’ transient ventricular dysfunction. Jpn Circ J. 2000, 64:715-719. 10.1253/jcj.64.715

10. Kagiyama N, Okura H, Kume T, Hayashida A, Yoshida K: Isolated right ventricular takotsubo cardiomyopathy. Eur Heart J Cardiovasc Imaging. 2015, 16:285. 10.1093/ehjci/jeu207

11. Donohue D, Ahsan C, Sanaei-Ardekani M, Movahed M-R: Early diagnosis of stress-induced apical ballooning syndrome based on classic echocardiographic findings and correlation with cardiac catheterization. J Am Soc Echocardiogr. 2005, 18:1423.E1-1423.E8. 10.1016/j.echo.2005.05.017

12. Akashi YJ, Nakazawa K, Kida K, et al.: Reversible ventricular dysfunction (takotsubo cardiomyopathy) following polymorphic ventricular tachycardia. Can J Cardiol. 2003, 19:449-451.

13. Novak G, Kross K, Follmer K, Brofferio A, Shirani J: Transient biventricular apical ballooning: a unique presentation of the "broken heart". Clin Cardiol. 2007, 30:355-358.

14. Bär H, Katus HA, Mereles D: Biventricular involvement in transient apical ballooning syndrome. Int J Cardiol. 2009, 133:79-80. 10.1016/j.ijcard.2007.11.034

15. Korlakunta H, Butkevich A, Muthupillai R, Cheong BYC: Biventricular takotsubo cardiomyopathy: cardiac magnetic resonance imaging as useful diagnostic tool. Tex Heart Inst J. 2011, 38:88-89.

16. Eitel I, Schuler G, Gutberlet M, Thiele H: Biventricular stress-induced (takotsubo) cardiomyopathy with left midventricular and right apical ballooning. Int J Cardiol. 2011, 151:63-4. 10.1016/j.ijcard.2010.05.017

17. Kurisu S, Inoue I, Kawagoe T, et al.: Takotsubo-like transient biventricular dysfunction with pressure gradients. Intern Med. 2005, 44:727-732. 10.2169/internalmedicine.44.727

18. Citro R, Caso I, Provenza G, Santoro M, Gregorio G, Bossone E: Right Ventricular Involvement and Pulmonary Hypertension in an Elderly Woman With Tako-Tsubo Cardiomyopathy. Chest. 2010, 137:973975. 10.1378/chest.09-0923

19. Daoko J, Rajachandran M, Savarese R, Orme J: Biventricular takotsubo cardiomyopathy: case study and review of literature. Tex Heart Inst J. 2013, 40:305-311.

20. Mrdovic I, Kostic J, Perunicic J, Asanin M, Vasiljevic Z, Ostojic M: Right ventricular takotsubo cardiomyopathy. J Am Coll Cardiol. 2010, 55:1751. 10.1016/j.jacc.2009.02.098 